\title{
ACCESO A MEDICACIÓN DE ALTO COSTO EN URUGUAY
}

\author{
ROSANA MANIKOWSKI \\ Médica Legista \\ Médica Asesora del Departamento de Medicina Forense \\ Poder Judicial. Uruguay \\ rmanikbor@gmail.com
}

RESUMEN: La aparición en el mercado de fármacos de alto costo y el creciente número de indicaciones médicas de fármacos no contemplados en las prestaciones sanitarias, han determinado un creciente número de acciones de amparo a nivel judicial. La judicialización de la medicina aumenta el trabajo judicial, el trabajo pericial y lleva a una derivación de recursos económicos de por sí limitados.

PALABRAS CLAVE: fármacos de alto costo, judicialización, recursos económicos.

ABSTRACT: The appearance of high-cost drugs on the market and the growing number of medical indications for drugs not included in health services have led to an increasing number of judicial protection actions. The judicialization of medicine increases judicial work, expert work and leads to a derivation of limited financial resources.

KEYWORDS: high-cost drugs, judicialization, economic resources.

SUMARIO: I. INTRODUCCIÓN - II. MARCO CONCEPTUAL Y NORMATIVO - III. DESARROLlO DEL TEMA - III.1 Fármacos de alto precio - III.2 Procedimiento abreviado - III.3 Acción de amparo - IV. CONCLUSIONES - V. BIBLIOGRAFÍA.

\section{INTRODUCCIÓN}

La creciente información general de la población en cuanto a salud, la mayor sobre vida global en enfermedades antes de peor pronóstico vital y funcional, la aparición en el mercado de fármacos de alto costo con mejores resultados que otras terapias y el creciente número de indicaciones médicas de fármacos no contemplados en las prestaciones institucionales ni en el formulario de medicamentos cubiertos por el Estado Uruguayo, han determinado un creciente número de acciones de amparo a nivel judicial.

Este aspecto de la judicialización de la medicina aumenta el trabajo judicial en lo civil y contencioso administrativo, el trabajo pericial y lleva a una derivación de recursos económicos de por sí limitados a aspectos no previstos en lo que se concluye una suerte de "amparización" de la medicina. No menos importante es la repercusión a nivel social en general y del paciente y familia en particular respecto a estas acciones de amparo y sus resultados, especialmente en la esperanza de los pacientes de obtener un fármaco con objetivo pretendidamente curativo y en el sentimiento de vulneración de su derecho a la salud y a la vida digna 


\section{MARCO CONCEPTUAL Y NORMATIVO}

El amparo, acción de amparar o proteger, "es la petición estatuida por algunas constituciones para ser tramitada ante un alto tribunal de justicia, cuando los derechos asegurados por ley fundamental no fueren respetados por otros tribunales o autoridades" (diccionario de la Real Academia Española).

Es una garantía del Derecho Público por medio de la cual el titular de un derecho quien considera se encuentra afectado ilegítimamente, por ejemplo un paciente respecto a su salud o calidad de vida, puede solicitar a un Juez la protección de ese derecho terminando así con la situación de vulneración.

Es una garantía de los Derechos Humanos, similar al habeas corpus aunque éste está descrito en la Constitución de la República; el juicio de amparo no está consagrado especialmente en la Constitución pero surge de la interpretación de varios de sus artículos, fundamentalmente el 7; también el 72 y 332:

- Artículo 7: "los habitantes de la República tienen derecho a ser protegidos en el goce de su vida, honor, libertad, seguridad, trabajo y propiedad. Nadie puede ser privado de estos derechos sino conforme a las leyes que se establecieron por razones de interés general".

- Artículo 72: "la enumeración de derechos, deberes y garantías hecha por la Constitución, no excluye los otros que son inherentes a la personalidad humana o se derivan de la forma republicana de gobierno".

- Artículo 332: "los preceptos de la presente Constitución que reconocen derechos a los individuos, así como los que atribuyen facultades e imponen deberes a las autoridades públicas, no dejarán de aplicarse por falta de la reglamentación respectiva, sino que ésta será suplida, recurriendo a los fundamentos de leyes análogas, a los principios generales de derecho y a las doctrinas generalmente admitidas".

La acción de amparo se dirige a los derechos humanos que surgen en la Constitución de acuerdo al artículo 72 y del artículo 1 de la Ley 16.011/88: "Acción de amparo; normas para que cualquier persona física o jurídica, pública o privada, pueda deducir la acción de amparo contra todo acto, omisión o hecho de las autoridades estatales o paraestatales, así como particulares que lesionen con ilegitimidad manifiesta sus derechos y libertades":

- Artículo 1: "cualquier persona física o jurídica, pública o privada, podrá deducir la acción de amparo contra todo acto, omisión o hecho de las autoridades estatales o paraestatales, así como de particulares que en forma actual o inminente, a su juicio, lesione, restrinja, altere o amenace, con ilegitimidad manifiesta, cualquiera de sus derechos y libertades reconocidos expresa o implícitamente por la Constitución (artículo 72), con excepción de los casos en que proceda la interposición del recurso de "habeas corpus".

- Artículo 2: "la acción de amparo sólo procederá cuando no existan otros medios judiciales o administrativos que permitan obtener el mismo resultado previsto en el literal B) del artículo $9^{\circ}$ o cuando, si existieren, fueren por las circunstancias claramente ineficaces para la protección del derecho. Si la acción fuera manifiestamente improcedente, el Juez la rechazará sin sustanciarla y dispondrá el archivo de las actuaciones". 
El juicio es muy breve y mayoritariamente en una única audiencia; la demanda debe ser presentada dentro de los 30 días desde la producción del hecho, por ejemplo la negativa del Ministerio de Salud Pública (MSP) a proveer un fármaco. En la audiencia se presentan las pruebas; la sentencia se dicta en ella o dentro de 24 horas y puede el juez solicitar diligencias para mejor proveer por ejemplo peritación médica.

La sentencia definitiva es apelable por improcedente; el recurso de apelación debe ser presentado en plazo de 3 días y elevado a Tribunal dentro de otros 3 días. El Tribunal de Apelaciones tiene un plazo de 4 días contados desde la recepción para expedirse.

Las medidas dispuestas en la sentencia son de ejecución inmediata después de notificada a las partes. La apelación contra la sentencia definitiva de Primera Instancia no suspende las medidas del amparo dispuestas en dicha sentencia.

Frente a la solicitud de protección del derecho a la salud la normativa nacional establece en la Ley 18. 211/07 referente al Sistema Nacional Integrado de Salud (SNIS):

- Artículo 1: "se reglamenta el derecho a la protección de la salud que tienen todos los habitantes residentes en el país y establece las modalidades para su acceso a servicios integrales de salud".

- Artículo 3: "son principios rectores del SNIS: la equidad, continuidad y oportunidad de las prestaciones; la solidaridad en el financiamiento general; la calidad integral de la atención que, de acuerdo a normas técnicas y protocolos de actuación, respete los principios de la bioética y los derechos humanos de los usuarios".

- Artículo 4: El SNIS tiene los siguientes objetivos: "alcanzar el más alto nivel posible de salud de la población mediante el desarrollo integrado de actividades dirigidas a las personas y al medio ambiente que promuevan hábitos saludables de vida, y la participación en todas aquellas que contribuyan al mejoramiento de la calidad de vida de la población".

Y en la Ley 18.335/08, Derechos y obligaciones de pacientes y usuarios de servicios de salud en:

- Artículo 2: "los pacientes y usuarios tienen derecho a recibir tratamiento igualitario y no podrán ser discriminados por ninguna razón ya sea de raza, edad, sexo, religión, nacionalidad, discapacidades, condición social, opción u orientación sexual, nivel cultural o capacidad económica".

- Artículo 7: "Todo paciente tiene el derecho a acceder a medicamentos de calidad debidamente autorizados por el MSP e incluidos por éste en el formulario terapéutica de medicamentos...".

Asimismo, en el Código de Ética Médica del Colegio Médico del Uruguay, Ley 19.286/14:

- Artículo 8: "el médico debe procurar los mejores medios científicamente aceptados de diagnóstico y tratamiento para sus pacientes así como el rendimiento óptimo y equitativo de dichos recursos" 
- Artículo 35: "el médico tiene derecho a prescribir el medicamento que considere más conveniente y el procedimiento diagnóstico o terapéutico que crea más acertado, en armonía con las prácticas reconocidas por la comunidad médica."

\section{DESARROLLO DEL TEMA}

En Uruguay los fármacos, dispositivos, planes de diagnóstico y tratamiento que son otorgados por las instituciones públicas y privadas integrantes del SINS se encuentran contempladas en el Plan Integral de Atención en Salud (PIAS) como canasta de prestaciones.

Los fármacos, dispositivos y procedimientos que no se encuentran en el PIAS, considerados de alto costo o precio, son financiados y brindados al paciente a través de la cobertura del Fondo Nacional de Recursos (FNR) que se sustenta a través de varios impuestos. Para el caso de los medicamentos cubiertos, éstos se entregan directamente al beneficiario o son enviados a la institución médica del paciente quien se encargará de su conservación y administración.

\section{III.1 Fármacos de alto precio.}

El FNR cuenta con el Formulario Terapéutico de Medicamentos (FTM) con el catálogo de fármacos, dispositivos y procedimientos cubiertos. Los medicamentos del FTM cubren específicamente determinadas patologías y los pacientes necesariamente deben cumplir con los criterios de inclusión para recibirlos, quedando por fuera pacientes que aún teniendo la enfermedad, no los cumplen por ejemplo por no estar en el estadio requerido. En el caso de un medicamento oncológico que tenga indicación en varios tipos de cánceres, el FTM puede contemplarlo para uno y no para otros.

\section{III.2 Procedimiento abreviado.}

Cuando un médico realiza una indicación y el fármaco no se encuentra ni en el PIAS ni en el FTM, el paciente debe solicitarlo al MSP a través de un procedimiento abreviado que permite celeridad en el suministro. Las solicitudes y la documentación aportada (informe de médico tratante, historia clínica) son analizadas por una Comisión Técnica Asesora que emite un informe técnico en el que se recomienda atender o no la solicitud; esta Comisión puede pedir informes técnicos, médicos, externos. Si no se hubiera entregado todo la documentación, se le da al paciente un plazo de 10 días corridos desde la fecha de la presentación para hacerlo.

El solicitante debe ser mayor de edad, y su solicitud debe ser hecha al Sr. Ministro de Salud Pública por escrito, junto con fotocopia de documento de identidad, informe del médico tratante y del Director Técnico del prestador de salud, historia clínica y paraclínica. El informe final de la Comisión será elevado al Sr. Ministro para la resolución final que será comunicada al interesado en un plazo de 20 días.

Si bien el proceso abreviado es justamente para dar una respuesta rápida, se han dado caso de demora de varios meses en dar la respuesta al paciente, incumpliendo con la normativa, en tanto que el paciente permanece en la incertidumbre; y en el caso de medicamentos oncológicos obviamente con la enfermedad progresando. Cuando la comisión no se expide 
dentro del plazo indicado, se lo considera denegado pudiendo entonces el paciente iniciar la acción de amparo.

Si el medicamento no está registrado en el MSP o está en el FTM no aplica el procedimiento abreviado; y en ese caso, la solicitud se hace por petición simple y el plazo de respuesta es de 150 días.

\section{III.3 Acción de amparo.}

Cuando la solicitud es denegada al paciente le queda la posibilidad de iniciar el juicio de amparo.

Existe un aumento en el número de amparos presentados tanto bajo auxiliatoria de pobreza a través del Consultorio Jurídico de Facultad de Derecho como por medio de abogados particulares. En dicho consultorio en 2011 se presentaron 8 acciones de amparo; en 2017 fueron 107 con 98\% de los casos ganados y un costo de US\$ 5.300.000 en medicamentos de alto precio. A octubre de 2018 se habían presentado 156 con 96\% de los casos ganados (Datos otorgados por el Dr. Juan Ceretta, Prof. del Consultorio Jurídico de Facultad de Derecho, Universidad de la República).

Respecto a las pericias médico legales con auxiliatoria de pobreza, en 2018 hasta iniciado el mes de octubre se realizaron 45 pericias. El resto del total de 156 corresponde a pericias solicitadas a las diferentes cátedras y en número mucho menor, a juicios en los que no se solicitó pericia médica.

En la demanda de amparo se explica la enfermedad, la negativa del informe del procedimiento abreviado y su ilegitimidad, se aporta el informe del médico tratante, la historia clínica y bibliografía que avala la indicación; y se solicita pericia médica con objeto pericial vinculado a la pertinencia del fármaco.

En la audiencia inicial el juez solicita el testimonio del médico tratante, que obviamente será coincidente con su informe, y el informe de un médico ajeno al proceso, legista/forense o especialista de las cátedras para que responda el objeto pericial.

Las preguntas al perito médico legista pueden ser:

- indicación en el caso concreto;

- razones científicas para la no inclusión del fármaco en el FTM;

- beneficios que le otorgaría el fármaco al paciente;

- balance riesgo beneficio o efectos adversos del fármaco;

- evolución del paciente sin el fármaco.

Las solicitudes de los fármacos son diversas:

- fármacos que se encuentran en el FTM para otra patología o con criterios de inclusión que no cumple el paciente; 
- fármacos que no se encuentran en el FTM pero que a nivel internacional están aprobados, que el laboratorio solicitó su inclusión y que el MSP la negó;

- fármacos aprobados a nivel internacional, que está autorizada su venta en el país pero que el laboratorio no solicitó su inclusión al FTM;

- fármacos que no han superado las diferentes fases de estudios clínicos, encontrándose por ejemplo en fase II;

- fármacos aprobados pero que no se encuentran en el país.

Estas situaciones son desconocidas por la mayoría de los pacientes solicitantes que ansían se les brinde la medicación, en ocasiones no para prolongar su vida sino para mantenerse la mayor cantidad de tiempo posible sin sintomatología; muchas veces consideran que la única razón de la negativa es económica.

El paciente se encuentra entonces litigando por su derecho a la salud y a la vida y se encuentra con una respuesta de falta de recursos económicos, también real. Si bien no figura descrito ni en prensa ni en las contestaciones de las demandas, evidentemente colisionan entonces el principio de autonomía del paciente y el de justicia distributiva; y colisiona también el de beneficencia del médico con el de justicia.

Entre los diferentes protagonistas: paciente, médicos, sociedad, sistema de salud y Estado resulta notoria una priorización de los principios bioéticos de autonomía y beneficencia por sobre el de justicia distributiva, lo que en un país de recursos económicos muy limitados puede resultar en una situación de carencia de recursos para otros planes de salud, por ejemplo a nivel primario. La situación actual es opuesta a las claras palabras de la Prof. Dra. María Teresa Rotondo, bioeticista uruguaya: "los tres principios de bioética son distintos entre sí; beneficencia y autonomía refieren al bien individual de una persona, mientras que el de justicia mira por el bien común; este bien de todos siempre es superior al bien de los individuos concretos, razón por la cual estos principios además de ser distintos guardan entre sí cierta jerarquía".

Existen algunas situaciones especiales a considerar:

- muchos de los fármacos oncológicos solicitados tienen indicación en cánceres en estadio IV, metastásicos con mal pronóstico vital a corto plazo, e inciden relativamente poco en la sobrevida global y en ocasiones más en la sobrevida libre de progresión de síntomas. Tras la sentencia favorable y con el fármaco administrado, por lo general el paciente muere a las pocas semanas o meses por lo que se desconoce si el fármaco influyó o no en la progresión de la enfermedad y si el gasto económico fue justificado;

- se solicitan y se accede a fármacos que se encuentran en fase II de ensayos clínicos por lo que carecen de las mayores garantías de seguridad y eficacia;

- se solicitan fármacos que están registrados en el MSP para su comercialización pero no se encuentran en el PIAS ni en FTM por lo que sólo pueden acceder a ellos pacientes con alto nivel adquisitivo lo que violaría el principio constitucional de igualdad;

- se solicitan y se accede a fármacos no registrados en el país con la consiguiente falta de reconocimiento del MSP como garante de los suministros; 
- un fallo favorable al paciente puede ser revocado en la segunda instancia con la consiguiente suspensión de la administración; sin embargo, en algunas situaciones, a pesar de la sentencia definitiva desfavorable al paciente, el MSP continua otorgando el fármaco lo que lleva a los interrogantes de porqué la negativa inicial, porqué la apelación y porqué en algunos pacientes sí y en otros no;

- tras la muerte de un paciente, el remanente del fármaco debería ser devuelto al MSP; sin embargo, en ocasiones los médicos lo utilizan en otro paciente quien luego de pocas semanas, muy probablemente deba iniciar una acción de amparo para continuar con la indicación.

\section{CONCLUSIONES}

El paciente puede acceder a un medicamento de alto precio como última posibilidad a través de una acción de amparo a nivel judicial. En dicha acción el paciente invoca legítimamente su derecho a la vida y salud, contemplados en la Constitución de la República.

En el país existe normativa referente a prestaciones médicas y diferentes formas de cobertura de fármacos.

El principio de autonomía y el de beneficencia claramente colisionan con el de justicia distributiva, Frente a una realidad de recursos económicos finitos y escasos, el no reconocimiento del principio colectivo como de mayor jerarquía origina la derivación de recursos económicos hacia situaciones no contempladas en la normativa lo que puede determinar la falta de recursos para planes de salud ya establecidos.

\section{BIBLIOGRAFÍA}

- CONSTitución DE LA REPÚblica ORIENTAL DEl URUGUAY.

- Rotondo De CASinelli, T., "Introducción a la Bioética”, en: Rev Urug Cardiol 2017; 32: 240-248.

- $\quad$ LEY 16.011/1988 ACCIÓN DE AMPARO. https://parlamento.gub.uy/documentosyleyes/leyes/ley/16011

- LEY 18. 211/2007 SiSTEMA NACIONAL INTEGRADO DE SALUD. https://parlamento.gub.uy/documentosyleyes/leyes/ley/18211

- LEY 18.335/2008 DERECHOS Y OBLIGACIONES DE PACIENTES Y USUARIOS DE SERVICIOS DE SALUD. https://parlamento.gub.uy/documentosyleyes/leyes/ley/18335

- LEY 19.286/2014 Código de ÉtiCA MÉdiCA DEl COlEgio MÉdico DEl URUGUAY. https://parlamento.gub.uy/documentosyleyes/leyes/ley/19286 